\title{
Lei HE
}

Guoliang LI

Lining XING

Yingwu CHEN

\section{AN AUTONOMOUS MULTI-SENSOR SATELLITE SYSTEM BASED ON MULTI-AGENT BLACKBOARD MODEL}

\section{AUTONOMICZNY WIELOCZUJNIKOWY SYSTEM SATELITARNY OPARTY NA WIELOAGENTOWYM MODELU TABLICOWYM}

\begin{abstract}
Traditional Earth observation satellite cannot work well in terms of emergencies, environmental uncertainties and scientific events discovery. Therefore, it is of significance to study the new generation of autonomous Earth observation satellite. In order to develop an autonomous satellite system with distributed and coordinated functions, this paper proposes an autonomous satellite system based on distributed multi-agent blackboard model. Multiple agents including functions of pre-processing, planning, scheduling and execution are designed. Agents share information and communicate through a blackboard which stores the task sequence, the action sequence and the satellite status. An adaptive rule-based heuristic scheduling algorithm and a forward search planning algorithm are proposed. The simulation experiments and computational results prove that the system can deal with scientific events discovery, satellite faults, cloud obscuration and emergencies without human intervention, which can greatly enhance the efficiency and reliability of Earth observation satellites. The validity of the proposed model and algorithm is proved.
\end{abstract}

Keywords: autonomous satellite, blackboard model, multi-agent, adaptive scheduling, planning.

\begin{abstract}
Tradycyjne satelity obserwacji Ziemi nie nadaja się do pracy w sytuacjach kryzysowych, warunkach niepewności środowiskowej oraz w okolicznościach związanych z odkryciami naukowymi. Dlatego też istotne znaczenie ma badanie nowej generacji autonomicznych satelitów obserwacji Ziemi. W celu opracowania autonomicznego systemu satelitarnego o rozproszonych i skoordynowanych funkcjach, w niniejszej pracy zastosowano rozproszony wieloagentowy model tablicowy. Zaprojektowano agenty, w tym funkcje wstępnego przetwarzania, planowania, harmonogramowania i wykonania. Agenty te wymieniaja między soba informacje $i$ komunikuja się za pośrednictwem tablicy (ang. blackboard), na której przechowywane sa informacje dotyczace sekwencji zadań i działań oraz stanu satelity. Zaproponowano adaptacyjny, regułowy, heurystyczny algorytm harmonogramowania oraz algorytm planowania metoda wyszukiwania w przód. Przeprowadzone eksperymenty symulacyjne oraz wyniki obliczeń dowodza, że omawiany system sprawdza się w przypadkach odkryć naukowych, awarii satelitarnych, zachmurzenia oraz w sytuacjach kryzysowych nie wymagajac interwencji człowieka, co może znacznie zwiększać wydajność i niezawodność satelitów obserwacji Ziemi. W pracy wykazano trafność proponowanego modelu i algorytmów.
\end{abstract}

Slowa kluczowe: satelita autonomiczny, model tablicowy, wieloagentowy, harmonogramowanie adaptacyjne, planowanie

\section{Introduction}

The Earth observation satellite (EOS) is becoming one of the major platforms for spatial information access, whose task is to get remote sensing data of specified targets on the surface of Earth according to the users' observation requests. EOS has the advantages of wide range and long imaging time, and is not restricted by national boundaries. Therefore, EOS is applied in many fields including disaster monitoring [21] and information support [15]. EOS is regarded as an important part of a country's comprehensive national power. The development of EOS has attracted the attention from all over the world.

The problem of EOS task planning and scheduling is mainly to study the resource allocation of multiple satellites and sensors, scheduling and planning multiple tasks, producing the action sequences and uploading to the satellites, i.e., deciding what the satellite should do at a certain time. Its working flow chart is shown in Fig. 1.

Currently, almost all the command and control instructions for satellite systems are issued by the ground control station and most of satellite tasks are time driven. The data acquired by the satellites

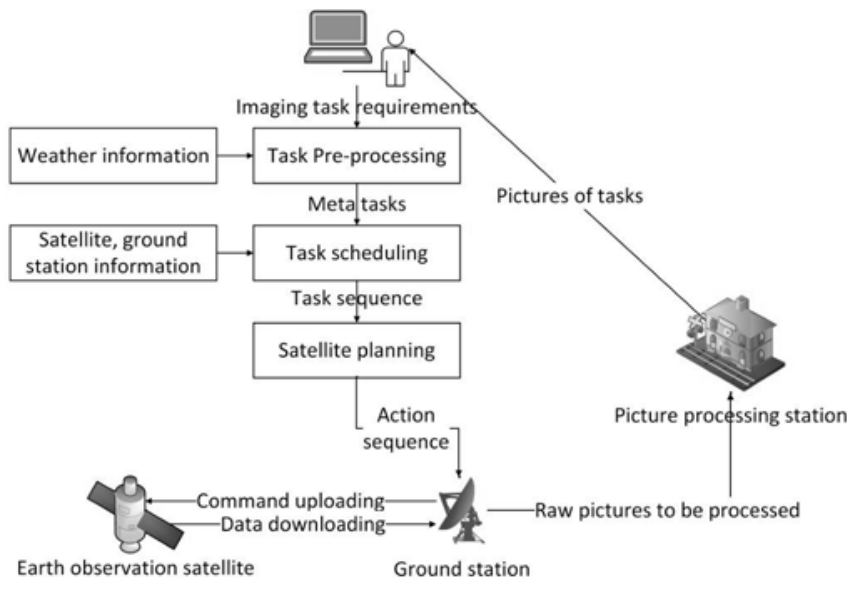

Fig. 1. Earth observation satellite management mode 
is also downloaded, processed and analysed by the ground stations. With the increasing number of the demands for the space information, this management mode is facing a series of challenges [17]:

- The satellite system needs the ability to deal with emergencies within a short period of time. However, due to the presence of satellite-ground communication delay and the limited communication bandwidth, the response time is too long to respond the emergencies and other uncertain changes;

- The deployment of ground stations is limited by geographical conditions and national boundaries;

- The number of satellites and the amount of information to be downloaded both increase dramatically, which brings difficulties to the control, communication, coordination and ground operations of the whole system.

Therefore, a new satellite management mode is necessary. An effective mode is to reduce the human intervention and make the satellite system more intelligent, so that it can work independently to complete the tasks. With the development of satellite technology, a new generation of satellite has a certain capability of computing and processing, which makes the development of autonomous satellite become the focus of research in the satellite field [10]. Compared with the traditional satellite, the autonomous satellite includes the following advantages: higher performance, better fault tolerance, higher reliability and lower maintenance cost. The system can deal with the uncertainties caused by environmental changes. The response time for emergencies will be shorten. Science events, such as floods and volcano eruptions, can be found by the satellite. The system also has high reconfigurability and extendibility.

There are several autonomous satellite in service currently. The US National Aeronautics and Space Administration (NASA) EO-1 [6] is an autonomous satellite and is able to discover science events on the Earth surface. Because of this autonomous management, EO-1 can save more than one million dollars every year and the events discovered annually worth more than 1.8 million dollars [7]. EO-1 uses SVM [4] to classify land, ice, cloud, etc. The software system on EO-1 is called ASE [24], and uses a scheduling method called CASPER. CASPER is quite fast and uses a simple iterative repairing algorithm to search for feasible solutions [24]. US Air Force's TacSat-3 [22] is another autonomous satellite designed to allow end users to send requests to the satellite directly. The satellite can respond to these requests automatically. FireBIRD is an autonomous satellite developed by German Aerospace Center (DLR) to discover and monitor high-temperature events such as forest fires [21]. However, the planning and scheduling processes are mostly done on the ground. The on-board part only optimizes the results and gives feedbacks according to the on-board information [18]. So, the application of FireBIRD is quite limited. French PLEIADES project started in 2000 and two autonomous satellites (Pleiades 1A and 1B) were launched in 2011 and 2012 respectively [12]. Pleiades has a powerful on-board autonomous planning ability. The planning process is regarded as a decision problem and solved by the constraint network on timelines (CNT) structure [3].

There are also some theoretical research. In 2010, European Space Agency (ESA) developed a distributed multi-agent system in its Distributed Agents For Autonomy (DAFA) study [5] and showed the advantages of performing on-board autonomy using agent technology in the satellite system. Araguz et al. [1] proposed a distributed satellite system to decompose the complex planning problem into several local planners. And they are coordinated by a global planner. The resource exchange management is not considered and there are no experimental results. Golkar's Federated Satellite Systems (FSS) [13] has similar ideas. They both use distributed modules to deal with complex missions but the FSS is mainly designed for constellations with multiple satellites.
From the above analysis, it can be seen that the current autonomous satellite systems are mostly mission-specific and the extendibility is low. And distributed modules and decomposition of tasks are two main trends of autonomous satellite development. Considering the advantages and disadvantages of these systems, this paper has designed a single autonomous multi-sensor satellite system based on the distributed blackboard model, which is a multi-agent system (MAS), to provide a reference for the research of the future autonomous satellite.

The remainder of this paper is organized as follows: Section 2 introduces the structure of this autonomous satellite system based on the blackboard model. Section 3 describes the mathematical model of the agile satellite observation task scheduling. Section 4 proposes an adaptive rule-based heuristic scheduling algorithm and a forward search planning algorithm. In section 5, simulation experiments are presented. Section 6 concludes the paper.

\section{The system structure based on the blackboard model}

\subsection{Blackboard model}

The first blackboard model was proposed for a speech understanding system [8]. The blackboard model is used to coordinate the relationship of each agent in the system, controlling the establishment of agents, communication and cooperation.

The basic idea of the blackboard model is as follows. A complex problem will be solved by multiple experts together, and the blackboard is a shared working space. All experts can see the blackboard. When the problem and initial data are written on the blackboard, the solving process starts. All the experts monitor the blackboard and when one finds the information on the blackboard is enough to support his work, he will start calculation and then write the results on the blackboard. The new information can be used by other experts. The process goes on until a final result is obtained and the complex problem is solved.

The blackboard model is widely used for establishing multi-agent intelligent systems $[2,20,23]$, especially for the ones with dynamic, uncertain and complex tasks. It provides a flexible and efficient method of communication among agents. The agents have different solving skills and work independently. Because the different modules do not interact with each other, the blackboard model is suitable for the system that already has some existing software. Adding new functions to this structure is quite convenient. And for this satellite system, some functions (such as task execution) already exist in a traditional satellite. Therefore, the blackboard model is quite suitable for this autonomous satellite system.

\subsection{System structure design}

As shown in Fig. 2, the structure realizes a distributed management of the functions of the satellites. The sub-systems have independent functions but are connected with each other to complete the imaging tasks.

The blackboard model is a BDI model, including three basic sets: the belief set, the desire set and the intention set. The three sets refer to the current resources the agents can use, the tasks the agents want to complete and the actions must be performed to complete the tasks respectively.

The blackboard module stores the status information of all the agents, including the task queue, the resource queue, belief and task execution evaluation results, which are the initial solution, partial solution, final solution and other system status. The function plug-ins "read from/write on" the blackboard by the subscriber and the releaser. All plug-ins exchange information through the blackboard and adjust the information on the blackboard. The task queue includes tasks 


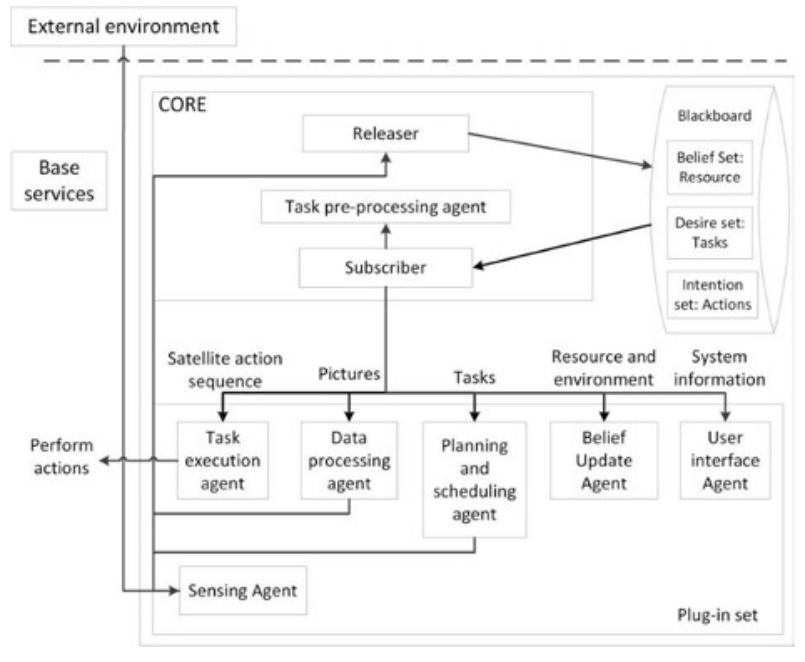

Fig. 2. Multi-agent system structure

to be planned which form the desire set $D$ of agents. The resource queue records the status of all the resources of the satellite. The status of these resources forms the belief set $B$ of the agents. The planning and scheduling agent is used to generate the final task execution plan, which is the action sequence of the satellite. And this sequence forms the intention set $I$ of the agents. The satellite completes tasks through the implementation of the actions.

The core module is used to provide the necessary basic functions for the satellite. Every single autonomous satellite has the same core structure.

The agent plug-in set includes some basic plug-ins which are the agents. These agents are also called knowledge source (KS). These agents are the function modules of the autonomous satellites, determining all the functions that can be used to complete a certain task. New agents of plug-ins can be added to extend the abilities of the satellites to meet the different demands. All the agents solve the problem related to their functions and work independently.

Subscriber and releaser: The subscriber is a monitoring mechanism of the blackboard model. It can select and activate a proper KS (agent) according to the information on the blackboard, to make the $\mathrm{KS}$ respond to the changes of information. Releaser is used to write the partial results from KSs on the blackboard.

The external environment: An autonomous satellite should have the ability to sense the environment and use the information to adjust plans and find new events on-line. We assume that this multi-sensor satellite carries a cloud detector, a visible optical sensor and an infrared sensor for observation, and there are some other sensors for monitoring the status of the satellite. The external environment has the following features:

- Partly-accessible: The cloud detector on the satellite can partly sense the cloud information in a few minutes, such as the location of clouds;

- Non-deterministic: Due to the real-time changes of environment and the complexity of the outer space, the implementation of an action can bring about different results, which also shows the importance of the autonomy;

- Non-episodic: When the satellite is executing a task, it should consider not only the current episode, but also the continuously changing environment as well as the information from other agents, and sometimes some simple predictions are also needed. Therefore, it is non-episodic;

- Dynamic: The environment is highly variable, such as clouds moving and various dynamic changes in the outer space;

- Continuous: The change of the environment is continuous and not discrete.
Therefore, the external environment of the satellite is very complex. Many uncertainties need to be considered.

There are many agents supporting each kind of functions in this satellite system. The function of each agent is as follows:

(1) Pre-processing agent: This agent can calculate the visible time windows (VTW) of each task according to the satellite track forecast and the locations of the targets. Here, VTW means the time period when the target is visible for the satellite. It is also known as the meta-task. Within the VTWs, the satellite can observe the targets and complete the imaging process.

(2) Planning and scheduling agent: This agent schedules the tasks according to the belief set and desire set and produces a task sequence with timestamps. According to the sequence, the satellite action sequence is then produced. This process is called planning. At the same time, this agent can also deal with some abnormal conditions to improve the reliability and reduce the maintenance cost.

(3) Belief agent: It is used to sense the status of resources and the satellite faults.

(4) Execution agent: Sensors and other devices on the satellite are controlled by this agent. At the same time, the latest information in the execution process is generated. For example, if a task is not executed as planned, such as delaying several seconds, the following task execution plan should be adjusted accordingly.

(5) Data processing agent: After an image is acquired, the agent can analyse it and check whether the target is successfully imaged. If not, it can generate a new task to image the target again.

(6) Sensing agent: This agent is used to sense the external environment and discover new tasks. By sensing the external environment, the impact of environmental uncertainties on imaging can be detected. The satellite can perform actions accordingly. The reliability can be increased. And new tasks of science events can be discovered.

(7) User interface agent: This agent is used to monitor the blackboard information. When the content of the blackboard changes, the interface is updated to facilitate the users to monitor the system. This agent can process the orders from the ground. Besides, the agent also allows us to upgrade and reconstruct the different modules on the satellite, such as adding a more efficient scheduling algorithm. This mechanic can extend the abilities of the satellite.

In a cycle of this system, the agents work as follows:

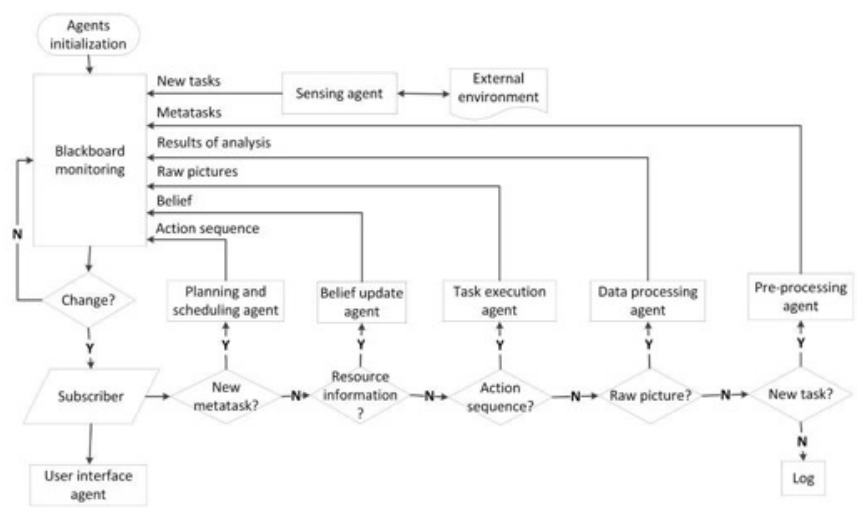

Fig. 3. Workflow of this system

Fig. 3 shows the relationship between the agents and the blackboard. The subscriber acts as a role of monitoring mechanism of the content on the blackboard. When the corresponding data is available, it dynamically selects and activates the appropriate agent. 


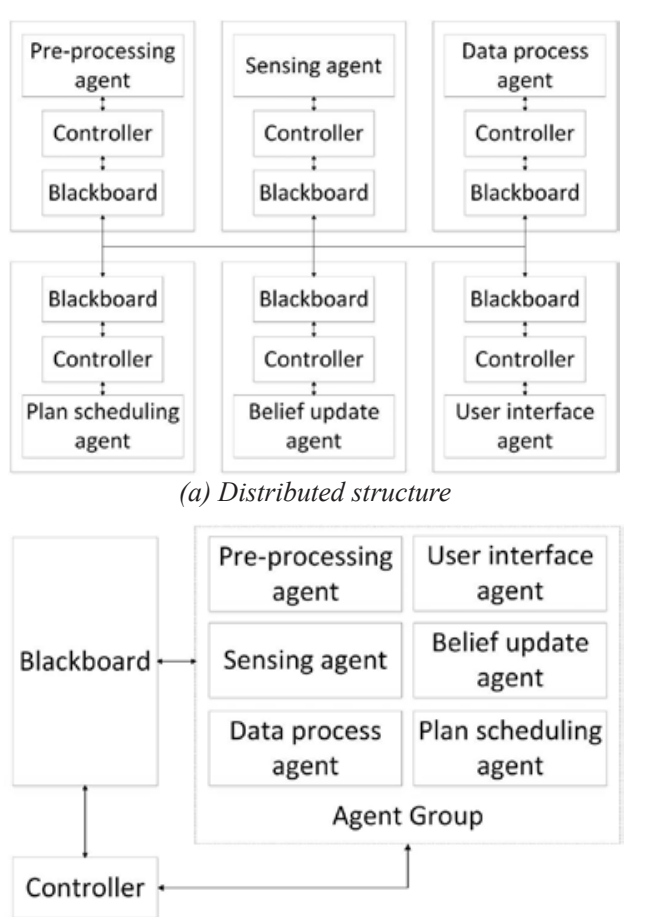

(b) Centralized structure

Fig. 4. Comparison of two kinds of hardware structures

Fig. 4 shows the hardware structure of this satellite system. In this paper, the autonomous satellite system adopts a distributed structure, which is shown in Fig. 4(a). To show the characteristics of this structure, we also give the centralized structure as a comparison in Fig. 4(b). There is only one blackboard in the system in the logic and software level (shown in Fig. 2), while in the physical and hardware level, there is one local blackboard in each agent, forming a distributed blackboard structure. This structure enables parallel and distributed computing of multiple agents on different units to cooperate and complete tasks. The local blackboards keep information consistency by the network broadcast. The contents in all the local blackboards are identical. Therefore, the agents in this system have a shared blackboard in the logic level, which provides data and intermediate results for the agents. Because the agents are distributed in different processors, all agents can work independently. The failure of one agent does not affect the ability of other agents, which can improve the reliability of the system. By contrast, in the centralized structure, there is only one blackboard in the physical level. All the agents work depending on the only one blackboard, making it difficult to realize the parallel computing of different agents. Besides, if the blackboard fails, the agents cannot work anymore. The reliability of this centralized structure is lower.

\subsection{Pseudo code}

The pseudo code of the planning and scheduling agent is shown to demonstrate the working principle.

\section{Pseudo code 1: Planning and scheduling agent}

public class SchedulePlan extends Agent \{

Releaser rel = new Releaser();

Subscriber sub = new Subscriber();

protected void setup ()\{

this.addBehaviour(new CyclicBehaviour() \{

public void action() \{

ACLMessage $\mathrm{msg}=$ receive () ;

if (msg != null) \{

tasklist $=$ sub.readtask () ; timelist $=$ sub.readVTW ()

tasklist $=$ schedule(tasklist,timelist $)$;

actoutlist $=$ plan(tasklist);

rel.writeschedule(tasklist);

rel.writeplan(actoutlist);

ACLMessage msg1 = new ACLMessage(ACLMessage.INFORM); msg1.setContent("action sequence ready"); send(msg1);

\section{Mathematical model of agile satellite task scheduling problem}

The main parameters involved in the mathematical model of agile satellite task scheduling are listed as follows:

- $T=\left\{t_{1}, t_{2}, \cdots, t_{N_{T}}\right\}:$ task set, where $N_{T}$ represents the total number of tasks;

- $P_{i}: P_{i} \in[1,10]$, the priority of task $t_{i}$, whose maximum is 10 and minimum is 1 ;

- $N_{i}$ : the number of VTWs of task $t_{i}$;

- $t_{i k}^{0}, t_{i k}^{m i d}, t_{i k}^{\text {end }}:$ the start time, middle time and end time of the $k^{\text {th }}$ VTW of task $t_{i}$;

- $g_{i}$ : the reward of task $t_{i}$;

- $d_{i}$ : the length of the observation window, i.e. the time required for imaging the task $t_{i}$;

- $t_{i j}^{\text {tran }}, t_{i j}^{\text {stable }}$ : the transition time and stable time needed from task $t_{i}$ to task $t_{j}$.

- Decision variable:

- $x_{i k}: x_{i k} \in\{0,1\}$, if the $k^{t h}$ VTW of task $t_{i}$ is chosen to observe the task, $x_{i k}=1$; otherwise, $x_{i k}=0$;

- $t o_{i}^{0}$, to $o_{i}^{\text {end }}:$ the start time and end time of the observation window.

The objective function is to maximize the total reward of all the tasks:

$$
\max P_{T}=\sum_{i=1}^{N_{T}} \sum_{k=1}^{N_{i}} x_{i k} g_{i}
$$

s.t.

$$
\forall t_{i} \in T, \sum_{k=1}^{N_{i}} x_{i k} \leq 1
$$

$$
\begin{gathered}
x_{i k}=1, \quad t_{i k}^{0} \leq t o_{i}^{0}<t o_{i}^{\text {end }} \leq t_{i k}^{\text {end }} \\
t o_{i}^{\text {end }}+t_{i j}^{\text {tran }}+t_{i j}^{\text {stable }} \leq t o_{j}^{0}
\end{gathered}
$$

$$
\text { to } o_{i}^{\text {end }}-t o_{i}^{0}=d_{i}
$$


Equation (2) means that each task can only be observed at most once. Equation (3) is the VTW constraint, restricting that the imaging time of each task must be inside the VTW of the task. Equation (4) is the transition time constraint, meaning that the imaging of the previous task does not affect the beginning of the latter task. This is the time-dependent characteristic of agile satellite scheduling. The transition time depends on the attitude of the satellite, which depends on the observation time of two successive observations. Equation (5) is the observation time constraint. The imaging must last for some time in order to ensure the integrity of the picture.

According to the characteristics of the agile satellite imaging process, the image with the best imaging quality can be acquired when the satellite is right above the target, i.e., when it is acquired at the middle of the VTW. Therefore, the reward of the task $t_{i}$ can be calculated by the following equation:

$$
g_{i}=\frac{P_{i}}{10}\left\lfloor 10-\frac{9\left|t-t_{i k}^{m i d}\right|}{t_{i k}^{m i d}-t_{i k}^{0}}\right\rfloor
$$

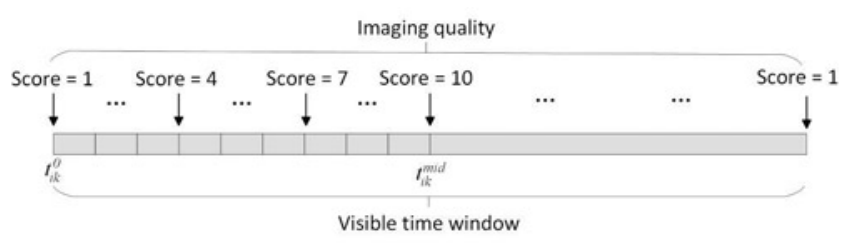

Fig. 5. The influence of imaging time on the imaging quality

As shown in Fig. 5, the highest score for the imaging quality is 10. And according to equation (6), 10 can be acquired in the middle of the VTW. When the picture is imaged at the two margins, the score is 1. Finally, the reward of a task can be calculated considering the priority and the imaging quality, as shown in equation (6).

\section{Autonomous satellite system algorithm design}

\subsection{Adaptive Rule-based heuristic scheduling algorithm}

The scheduling problem of agile satellite is a typical NP-Hard combinatorial optimization problem [16], whose solution space is very large, and with the increasing number of the tasks, the complexity of the problem grows exponentially. Besides, because the computing resources on the satellite are limited, the scheduling and planning processes cannot be too complex, otherwise it will influence the execution of the plan. Therefore, this paper uses an adaptive rule-based heuristic algorithm (ARHA) to generate a feasible and near optimal schedule.

We have designed four operators to sort the tasks to be scheduled. They are:

- Priority sorting: tasks with higher priority will be considered preferentially.

- Opportunity sorting: tasks with fewer VTWs will be chosen first because those with more VTWs are easier to schedule.

- Observation time sorting: this operator chooses tasks whose VTWs are earlier.

- Conflict sorting: the operator sort the tasks by a descending order of the overlapping degree. Here the overlapping degree means the length of time one VTW overlaps with other VTWs. Because the tasks with higher overlapping degree may have conflict with other tasks, they might reduce the total reward.

To increase the adaptability of this algorithm, we have designed an adaptive mechanism. Each operator has a score and a weight and both of them depend on the performance of the operators. We regard every 50 times of scheduling as a section. At the end of each section, the weight for each operator is updated. The score is updated in every time of scheduling and initialized at the end of each section. Every time an operator is chosen, its score is update according the following equation:

$$
s_{i}{ }^{\prime}=s_{i}+\gamma
$$

where, $s_{i}$ and $s_{i}{ }^{\prime}$ are the current score and updated score respectively, and $\gamma$ is the reward rate, which equals to the proportion of the total reward divided by the total priority. At the end of each section, the weights of operators are updated:

$$
\omega_{i}{ }^{\prime}=(1-\lambda) \omega_{i}+\lambda s_{i} / \sum_{i=1}^{4} s_{i}
$$

where, $\omega_{i}$ is the historical weight and $\lambda \in[0,1]$ is a reaction factor controlling the sensitiveness of the weights.

Roulette wheel mechanism is used to choose the operators. And the probability one operator can be chosen is calculated as follows:

$$
p_{i}=\omega_{i} / \sum_{j=1}^{4} \omega_{j}
$$

The flow of the algorithm is as follows:

Step 1: Get the task information and the satellite VTW data;

Step 2: Choose a sorting operator using the roulette wheel mechanism. Generate a task sequence according to this operator. If one operator cannot determine the order, choose another operator until the tasks are sorted;

Step 3: Set the counter $k=0$;

Step 4: Find all VTWs of task $t_{k}$;

Step 5: Find the n VTWs with the smallest overlapping degree;

Step 6: Calculate the best imaging quality of each VTW;

Step 7: Choose the VTW with the highest imaging quality;

Step 8: Update the scores of all the operators. If this is the end of a section, update the weights of all the operators and initialize the scores;

Step 9: If $k=\mathrm{n}$, or all the tasks are successfully scheduled, or the maximum iteration time is met, the algorithm terminates; otherwise, go to Step 3.

The flow chart of scheduling algorithm is shown in Fig. 6:

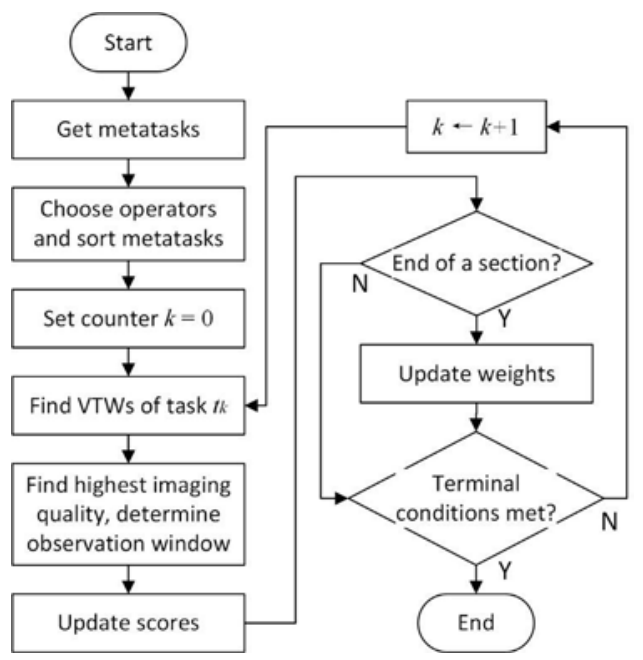

Fig. 6. Flow chart of scheduling algorithm 


\subsection{Cutting the VTWs}

Before determining the best imaging quality of a VTW, the VTW should be cut in order to meet the transition time constraint. By judging the relationship between the determined observation time window and the VTW, the VTW can be cut accordingly. Assuming that task $t_{j}$ has been determined for observation. And $k^{\text {th }}$ VTW of task $t_{i}$ can be cut according to the observation time window of task $t_{j}$. As shown in Table 1, the VTW is cut according to the six different relationships.

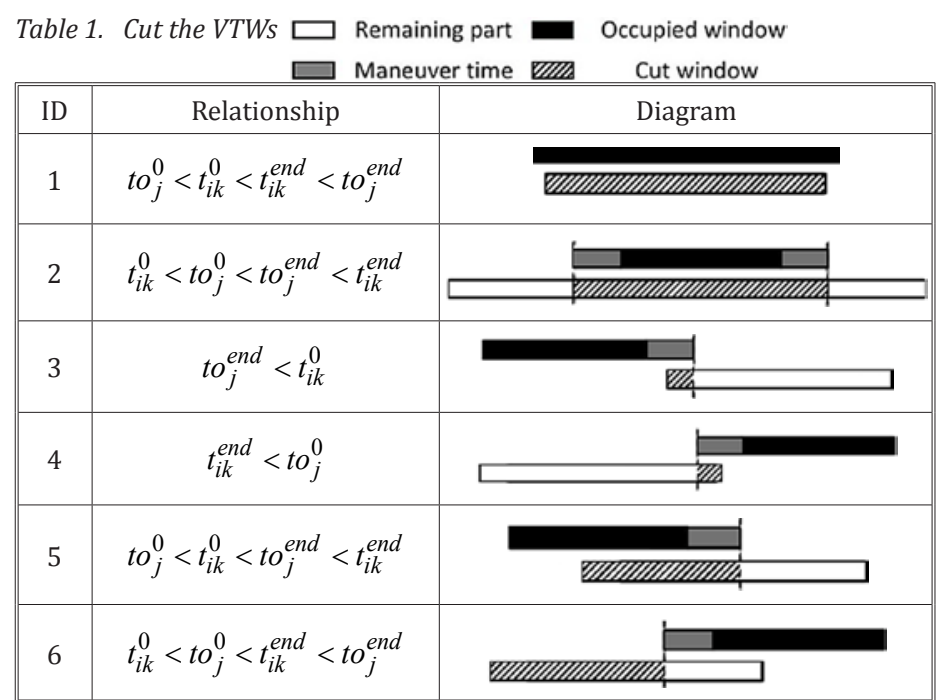

\subsection{A forward search algorithm based on STRIPS}

The satellite action sequence can be generated according to the task sequence produced in the above section. A forward search algorithm based on STRIPS [9] is used. The STRIPS operator can describe an action as a process from a previous state to a subsequent state. Typically a STRIPS operator consists of the following three parts:

- Set PC: the preconditions of the operator. An action can be performed only when all the preconditions in PC are met;

- Set D: delete list. It shows the states changed when an action is performed;

- Set A: add list. It includes the changes brought by an action.

According to the above description, a typical satellite action, such as turning on the camera, can be described by STRIPS as the following format:

\section{Pseudo code 2: Action "turn on the camera" STRIPS}

TurnOnCamera()

PC: CameraOff( ()$\wedge$ CameraPreheated ()$\wedge$ Ontime ()

D: CameraOff()

A: CameraOn ()$\wedge$ PictureCaptured(task.duration)

Therefore, for the action of turning on the camera, the preconditions include: the camera is off, the camera preheating has been finished and the imaging time is due; delete list includes the state that the camera is off; the add list includes: the camera is on and the photo is imaged. The preconditions of the next action "turn off the camera" are PictureCaptured () and Ontime (). Thus, when the image is captured, the camera will be turned off.

As shown above, if an action's preconditions are all met, this action will be performed. Using a forward search algorithm, the action sequence can be generated.

\section{Simulation experiments and results discussion}

A laptop with Intel Core i5-3317U CPU 1.70GHz, 8G memory and Windows 10 system is used to develop and run the system. The developing platform is JDK 1.8+ NetBeans IDE 8.1 + Jade 4.0.

\subsection{Online events simulation}

In order to show the system's autonomy characteristics, this paper has designed four kinds of online events:

\subsubsection{The discovery of new tasks}

If there is no task on the blackboard, the system will be in a waiting state. By clicking the user interface button "new task", we simulate the process that the sensing agent (Sense) discovers a new task and the task is written on the blackboard.

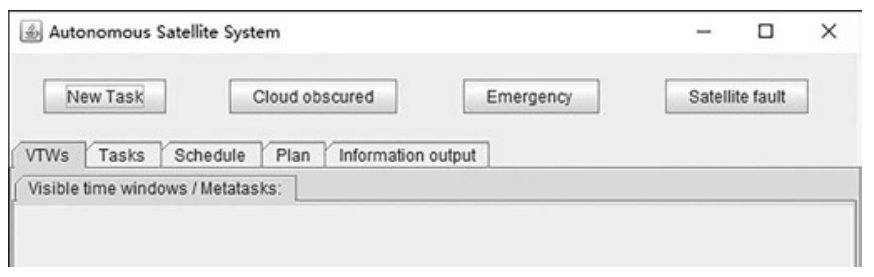

Fig. 7. Autonomous satellite system interface

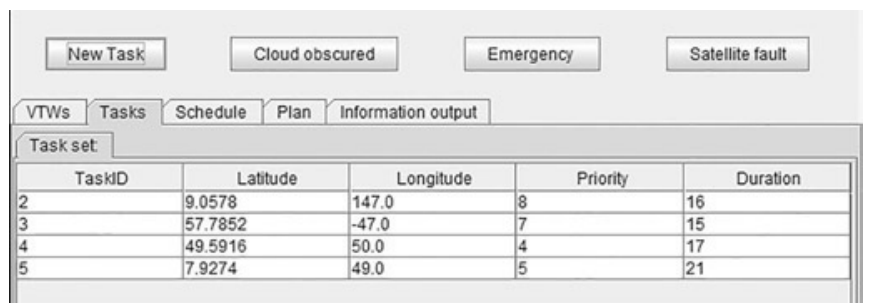

(a) Task list

\begin{tabular}{|c|c|c|c|c|}
\hline \multicolumn{5}{|c|}{ Visible time windows / Metatasks: } \\
\hline WinlD & TaskID & Startime & EndTime & Duration \\
\hline 4 & 2 & 2013-04-20 07:29:25 & 2013-04-20 07:29:35 & 10.6 \\
\hline$\frac{7}{5}$ & $\frac{2}{2}$ & 2013-04-20 20:15:07 & $2013-04-2020: 20-22$ & 314.7 \\
\hline 6 & 3 & 2013-04-20 06:58:25 & 2013-04-20 06:58:49 & 24.0 \\
\hline 7 & 3 & $2013-04-2008: 40: 06$ & $2013-04-2008: 45: 07$ & 301.3 \\
\hline 8 & 3 & $2013-04-2020: 46: 22$ & 2013-04-20 20:52:50 & 387.7 \\
\hline 9 & 3 & $2013-04-2022: 27: 14$ & 2013-04-20 22:33:19 & 364.5 \\
\hline$\frac{10}{10}$ & $\frac{5}{4}$ & $2013 \cdot 04-2003: 56: 29$ & $\mid 2013-04-2004: 01: 31$ & 301.9 \\
\hline 11 & 4 & $2013-04-2013: 41: 11$ & 2013-04-20 13:48:03 & 412.3 \\
\hline 12 & 4 & $2013-04-2015: 21: 47$ & $2013-04-20 \quad 15-24 \cdot 40$ & 1728 \\
\hline 13 & 5 & $2013-04-2014: 15: 53$ & $2013-04-2014-21: 14$ & 321.3 \\
\hline
\end{tabular}

(b) VTW list

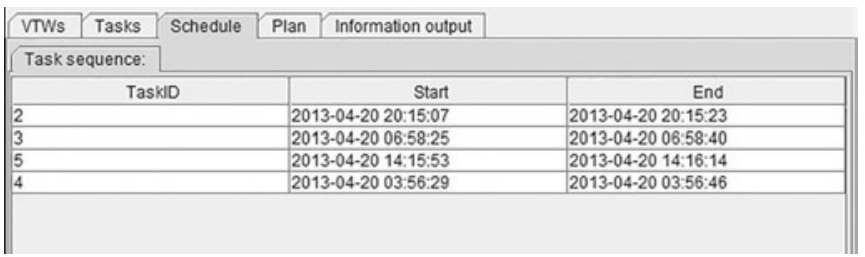

(c) Schedule / task sequence with timestamp

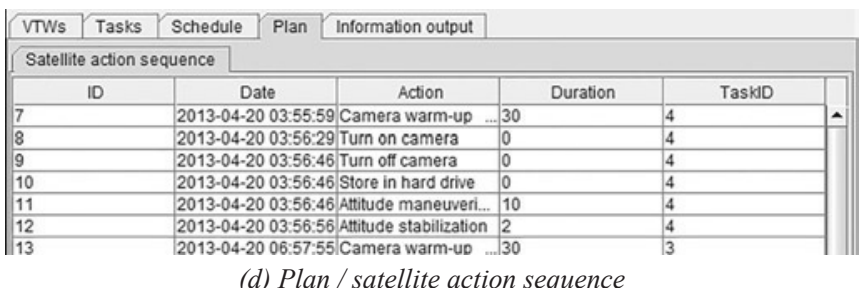

Fig. 8. System screenshots for the new task discovery

Fig. 7 shows the interface of this system. The above four buttons, respectively, represent the four types of events. The VTW window is used to display a list of all the VTWs whose tasks are not executed. 


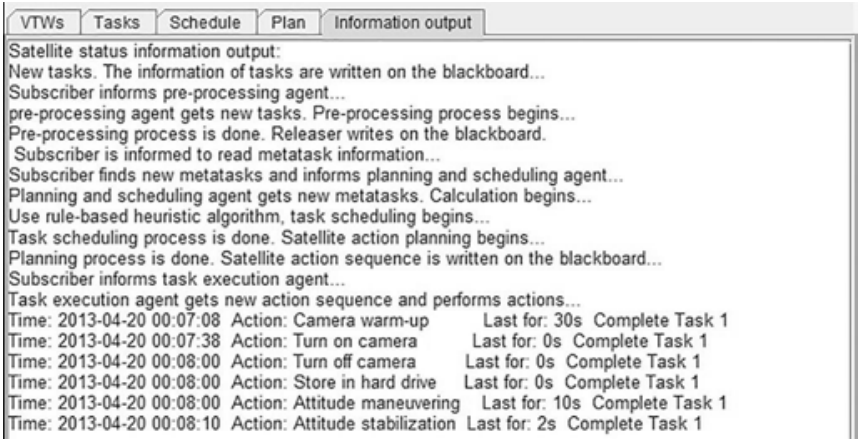

(e) System information after task 1 is executed

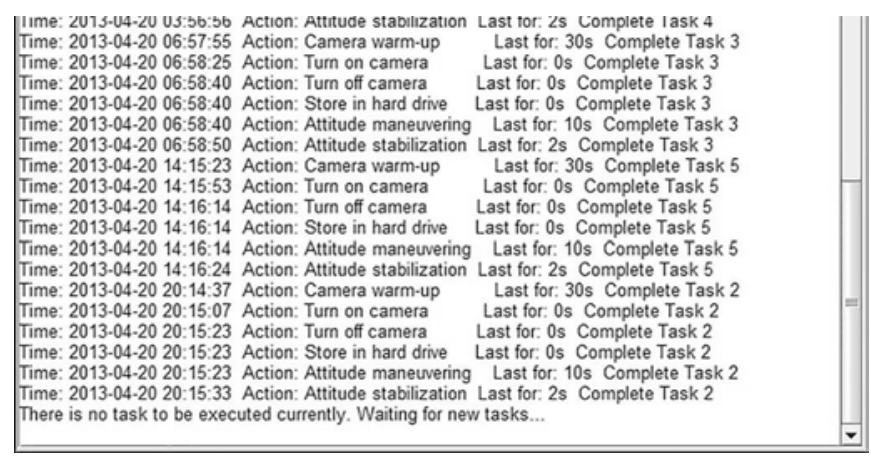

(f) System information after all tasks are executed

Fig. 8. (continued) System screenshots for the new task discovery

When one task is executed, all the corresponding VTWs will be deleted from the blackboard. The task window lists all the tasks that are not executed; schedule window and plan window show the schedule list and action list that are not performed respectively. The information window is used to display the information of the satellite.

Here we assume that the satellite finds five new tasks. Fig. 8(a)(e) show the screenshots after the first task is executed.

Fig. 8(a) shows that task 1 is removed from the blackboard after the execution. Fig. 8(b)-(d) show that all the VTWs, task sequence and action list about task 1 are removed from the blackboard. From Fig. 8(e) we can monitor the satellite actions and all the information when the satellite is processing the event. Fig. 8(f) is the screenshot after all the five tasks are executed.

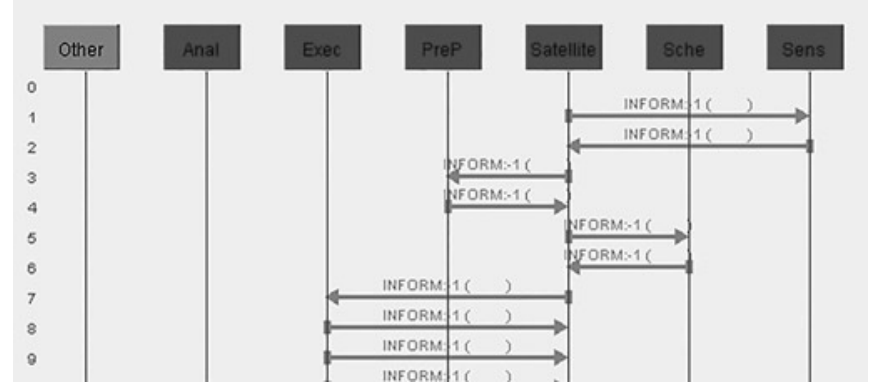

Fig. 9. Information flow between Agents

Fig. 9 shows the information flow between agents. "Anal" is the data processing agent. "Exec" is the execution agent. "PreP" is the pre-processing agent. "Satellite" is the user interface agent. "Sche" is the planning and scheduling agent. "Sens" is the sensing agent. After the discovery of new tasks, the agents cooperate with each other. The whole process of pre-processing, scheduling, planning, execution and picture analysis are performed automatically without human intervention.

\subsubsection{The image is obscured by clouds}

In the real situation, after imaging a target, the picture will be analyzed by the data processing agent to check the usability of the picture. In our simulation, after imaging a task, the ID of this task will be recorded. If the system detects "cloud obscured" button is clicked, the last picture imaged is obscured by the clouds.

Here, after task 4 is executed, we click the "cloud obscured" button. Fig. 10(a)-(c) are the screenshots:

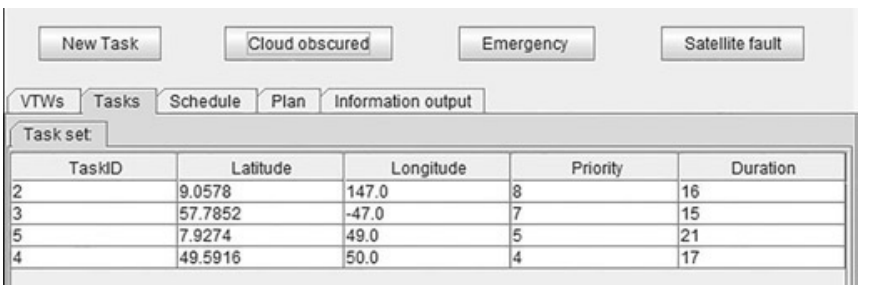

(a) Task list

\begin{tabular}{|c|c|c|c|c|}
\hline \multicolumn{5}{|c|}{ Visible time windows / Metatasks: } \\
\hline WinlD & TaskID & Startime & EndTime & Duration \\
\hline Ton & Tosion & $2013-04-2007: 29: 25$ & 2013-04-20 07:29:35 & 10.6 \\
\hline$\frac{7}{5}$ & $\frac{2}{2}$ & 2013-04-2020:15:07 & $2013-04-2020: 20: 22$ & 314.7 \\
\hline 6 & 3 & $2013-04-2006: 58: 25$ & $2013-04-2006: 58: 49$ & 24.0 \\
\hline 7 & $\frac{5}{3}$ & $2013-04-2008: 40: 06$ & $2013-04-2008: 45: 07$ & 301.3 \\
\hline 8 & 3 & $2013-04-2020: 46: 22$ & $2013-04-2020-52 \cdot 50$ & 387.7 \\
\hline 9 & 3 & $2013-04-2022: 27: 14$ & $2013-04-2022: 33: 19$ & 364.5 \\
\hline 13 & $\frac{5}{5}$ & $2013-04-2014: 15: 53$ & $2013-04-2014: 21: 14$ & 321.3 \\
\hline 11 & 4 & $2013 \cdot 04-2013: 41: 11$ & $2013 \cdot 04-2013: 48 \cdot 03$ & 4123 \\
\hline 12 & 4 & 2013-04-20 15:21:47 & $2013-04-2015: 24: 40$ & 172.8 \\
\hline
\end{tabular}

(b) VTW list

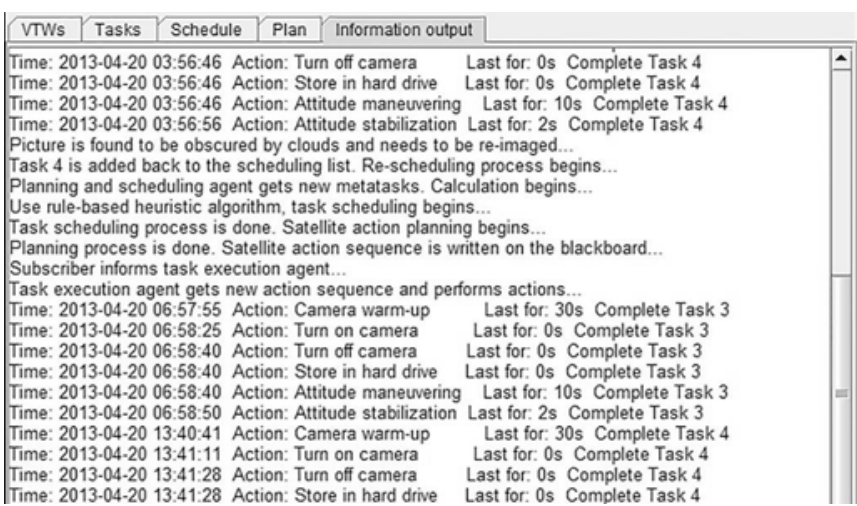

(c) System information after task 4 is obscured

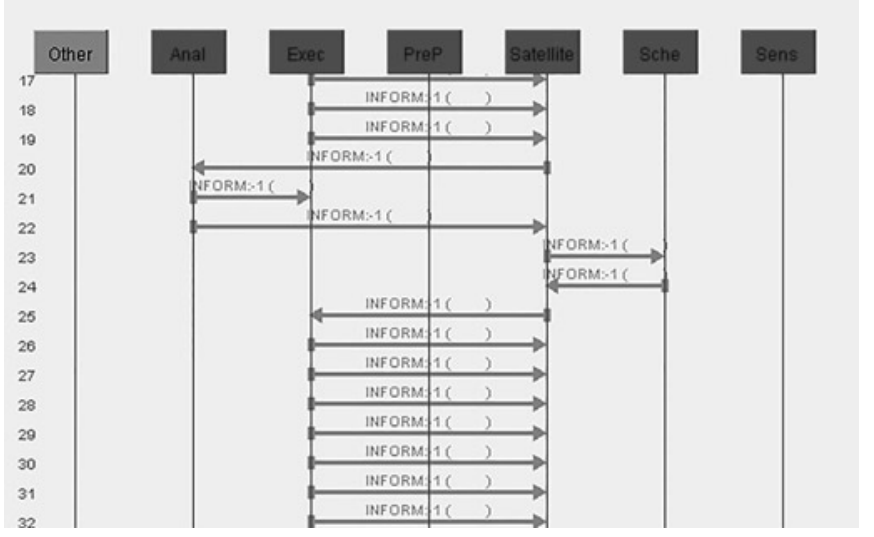

(d) Information flow for cloud obscuration

Fig. 10. Screenshots for the cloud obscuration

From Fig. 10(a), it can be seen that task 4, which is already executed, is added back to the blackboard. In Fig. 10(b), the VTWs of task 4 is added back too. But the VTW around 3:56 is deleted because the time has passed. In Fig. 10(c), we can find that after task 4 was ex- 
ecuted at around 3:56, the data processing agent find that task 4 is obscured by clouds. Therefore, the picture is deleted from the hard drive and task 4 should be re-imaged, triggering the on-board re-scheduling process. Then task 4 is re-imaged at around 13:41 according to the results of the re-scheduling process.

Fig. 10(d) shows the information flow between agents. We can see that the data processing agent (Anal) sends two message, informing task execution agent to wait and informing user interface agent to update the user interface. Because task 4 is added back to the blackboard, the planning and scheduling agent are activated.

To sum up, after the picture is obscured by the cloud, the agents trigger the online re-scheduling process, delete the useless picture and re-image task 4 . The storage is saved and useful data can be downloaded, increasing the reward rate and reliability.

\subsubsection{Emergency task}

This button represents the situation that a task with a higher priority has arrived or been found and if this task conflicts with some deter-

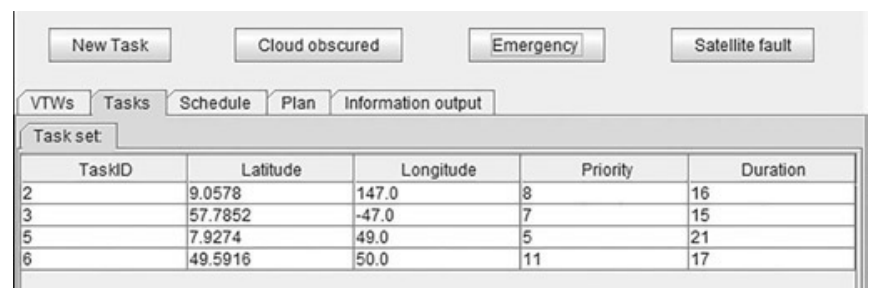

(a) Task list

\begin{tabular}{|c|c|c|c|c|}
\hline \multicolumn{5}{|c|}{ Visible time windows / Metatasks: } \\
\hline WinlD & TaskID & StartTime & EndTime & Duration \\
\hline 4 & 2 & $2013-04-20 \quad 07: 29: 25$ & $2013-04-2007: 29: 35$ & 10.6 \\
\hline 5 & 2 & 2013-04-20 20:15:07 & $2013-04-2020: 20: 22$ & 314.7 \\
\hline 6 & 3 & $2013-04-2006: 58: 25$ & $2013-04-2006-58: 49$ & 24.0 \\
\hline 7 & 3 & $2013-04-2008: 40: 06$ & $2013-04-2008: 45: 07$ & 301.3 \\
\hline 8 & 3 & $2013-04-20 \quad 20: 46: 22$ & $2013-04-2020: 52-50$ & 387.7 \\
\hline 9 & 3 & 2013-04-20 22:27:14 & $2013-04-2022: 33: 19$ & 364.5 \\
\hline 13 & 5 & 2013-04-20 14:15:53 & $2013-04-2014: 21: 14$ & 321.3 \\
\hline 11 & 6 & $2013-04-20 \quad 06: 58: 25$ & $2013-04-2006: 58: 49$ & 24.0 \\
\hline 12 & 6 & $2013-04-20 \quad 15: 21: 47$ & $2013-04-2015: 24: 40$ & 172.8 \\
\hline
\end{tabular}

(b) VTW list

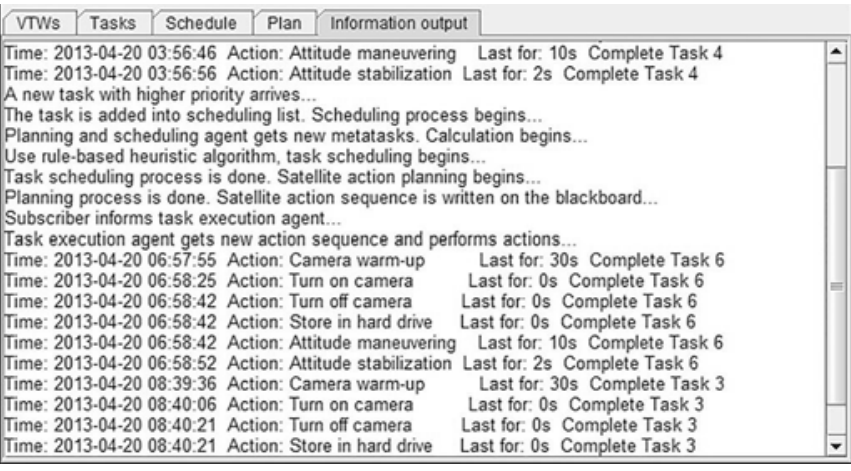

(c) System information when emergency arrives

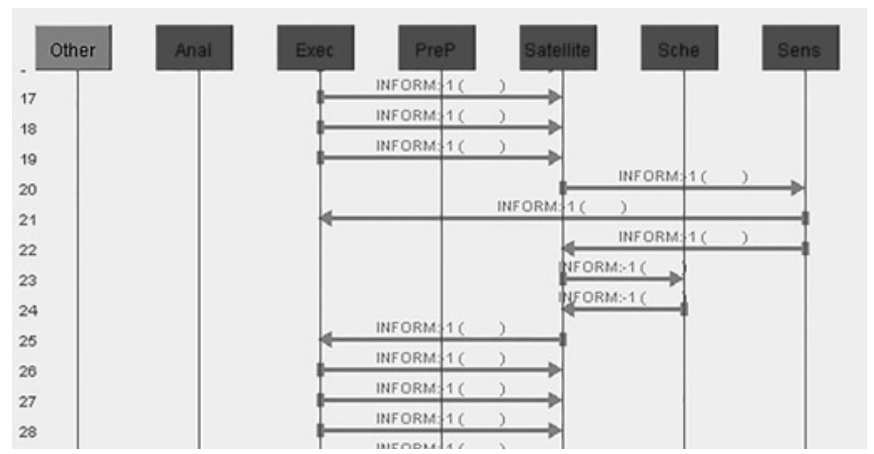

(d) Information flow for processing emergency

Fig. 11. Screenshots for the processing emergency mined tasks, a re-scheduling and re-planning process will be triggered and the tasks with lower priorities will be $\mathrm{re}^{-}$scheduled to meet the requirement of the task with the higher priority.

According to the original plan, after the execution of task 4 , task 3 should be executed (as shown in Fig. 8(d)). Here, we add an emergency task with priority 11 after the execution of task 4 and make the new task conflict with task 3 . The screenshots of the system are shown in Fig. 11(a)-(c).

In Fig. 11(a), there is a new task 6 listed in the task queue, and its priority is 11. Fig. 11(b) shows that the VTWs of task 6 conflict with those of task 3 . Therefore, task 6 with higher priority should be imaged first. In Fig. 11(c), we can find that after execution of task 4, a new task with a higher priority arrives. And its VTWs conflict with those of task 3 . In the re-scheduling process, the time for executing task 3 is used to execute task 6 . And task 3 is postponed to be executed at $8: 39$.

\subsubsection{Satellite fault}

This button simulates the existence of a satellite fault. If this button is clicked, the system will wait for five seconds (the speed of the simulation is 1000 times of the reality. Therefore five seconds in simulation is equivalent to 1.5 hours in reality), no observation task can be executed during this time period.

Fig. 12(a)-(b) are the screenshots after a satellite fault is detected. After the execution of task 4, a satellite fault occurs and lasts about 1.5 hours. After the fault is fixed, the VTW for imaging task 3 has passed.

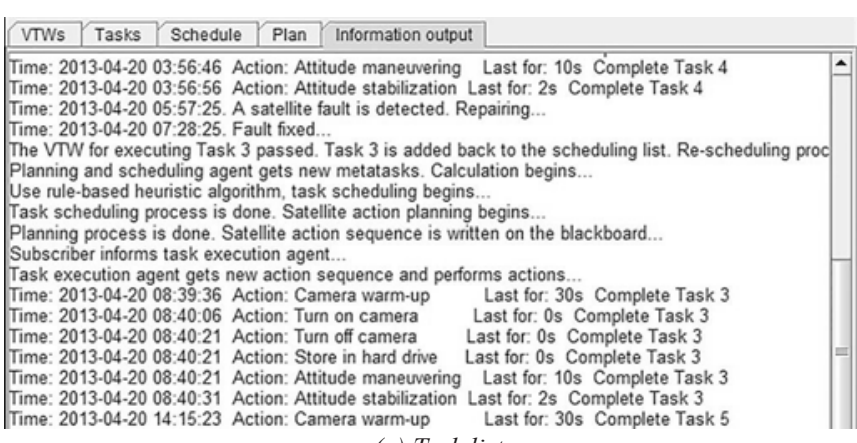
(a) Task list

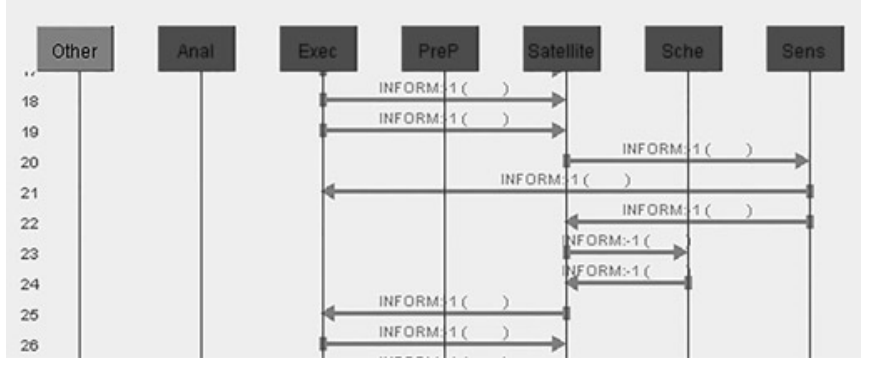

(b) System information when emergency arrives

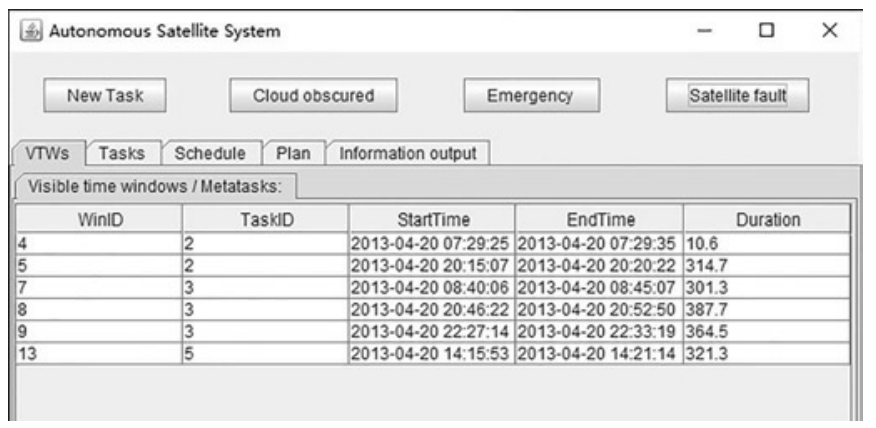

(c) Information flow for processing satellite fault

Fig. 12. Screenshots for processing the satellite fault 
Table 2. Results of comparison of algorithms' performance

\begin{tabular}{||c|c|c|c|c|c|c|c|c||}
\hline \multirow{2}{*}{$\begin{array}{c}\text { Scenario } \\
\text { ID }\end{array}$} & \multirow{2}{*}{$\begin{array}{c}\text { Number } \\
\text { of Tasks }\end{array}$} & \multirow{2}{*}{$\begin{array}{c}\text { Number } \\
\text { of VTWs }\end{array}$} & \multicolumn{3}{|c|}{ Reward rate(\%) } & \multicolumn{3}{c||}{ CPU time (s) } \\
\hline 1 & 1 & 2 & 100 & 100 & 100 & 0.01 & 0.57 & 0.09 \\
\hline 2 & 3 & 7 & 100 & 100 & 100 & 0.02 & 1.19 & 0.43 \\
\hline 3 & 5 & 13 & 100 & 100 & 100 & 0.02 & 4.42 & 1.29 \\
\hline 4 & 10 & 23 & 100 & 100 & 100 & 0.02 & 936.53 & 1.88 \\
\hline 5 & 11 & 26 & 100 & 100 & 100 & 0.02 & 10385.10 & 2.42 \\
\hline 6 & 12 & 26 & 100 & - & 100 & 0.03 & - & 2.90 \\
\hline 7 & 50 & 117 & 100 & - & 100 & 0.04 & - & 27.57 \\
\hline 8 & 100 & 236 & 100 & - & 98.99 & 80.63 & - & 143.66 \\
\hline 9 & 150 & 367 & 100 & - & 100 & 90.62 & - & 307.70 \\
\hline 10 & 200 & 466 & 99.49 & - & 98.48 & 612.69 & - & 729.68 \\
\hline 11 & 250 & 596 & 100 & - & 100 & 132.51 & - & 1059.17 \\
\hline 12 & 300 & 701 & 99.66 & - & 98.32 & 962.93 & - & 916.74 \\
\hline
\end{tabular}

Therefore, a re-scheduling process is triggered to re-image task 3. In Fig. 12(b), we can find that after the fault is fixed, the re-scheduling process postpones task 3 to its second VTW (8:39) to be executed. In Fig. 12(c), the sensing agent (Sense) finds the fault and informs the task execution agent to wait and the user interface agent to update. After the fault is fixed, the planning and scheduling agent starts the re-scheduling process. The whole fault discovering and fixing process and scheduling process are conducted by the multi-agent structure, showing a high reliability of the satellite system.

\subsection{Algorithm performance comparison}

To test the performance of the proposed adaptive rule-based heuristic scheduling algorithm (ARHA), we compare it with the ILOGCPLEX solver 12.6 and the ant colony optimization (ACO). ILOGCPLEX solver 12.6 is a powerful software for solving constraint programming problem. The algorithm of the CPLEX solver is an exact algorithm, which can always find the optimal solution. ACO is an evolutionary algorithm for path optimization. We regard the sequence of tasks as the ants' path and use ACO to optimize it. We use the improved ACO proposed in paper [14]. For ARHA, the weight update parameter $\lambda=0.5$ and the maximum iteration is 5000 . For ACO, the parameters are set according to paper [14].

In this section, 12 scenarios are designed to test the performances of the above algorithms. In each scenario, a certain number of targets are randomly distributed worldwide. Each algorithm is run for five times and the average results are reported in Table 2.

For the exact algorithm of CPLEX, the solution space of this agile satellite scheduling problem is too big. We can see that the CPU running time increases exponentially with the number of tasks. And for the scenario with 12 tasks, the CPU running time becomes too long to find the optimal solution. Therefore, in practice, CPLEX cannot be used in this kind of scheduling problem, especially for this autonomous satellite online scheduling problem.

For the other two algorithms, ACO and ARHA both performs very well in terms of the reward rate. In most cases, the reward rate is $100 \%$ and ARHA is slightly better than ACO for Scenario 8, 10 and 12. As for the running CPU time, ARHA performs much better than ACO. In almost all the scenarios, ARHA uses less time to find a near optimal solution. The proposed heuristics in ARHA are helpful to guide the algorithm to find a near optimal solution in a large solution space efficiently.

The efficiency and effectiveness of ARHA for this online autonomous satellite task scheduling problem is proved.

\subsection{Reliability comparison}

For a traditional non-autonomous satellite, the above four kinds of events cannot be finished automatically. The satellite cannot discover events by itself. Typically, it is the ground station which receives requirements from users and then uploads the commands. And because there is no computational ability on-board and the commands uploaded are fixed, the satellite cannot deal with any uncertainties including cloud coverage, emergencies and satellite faults.

Here, we firstly compare the performance of traditional satellite and autonomous satellite under the consideration of the cloud information.

To represent the cloud information, a definition called cloud-obscuring time window (CTW) [19] is used. It refers to the time period that the target is obscured by clouds. All the ATWs should be cut according to CTWs to remove the time period that targets are obscured. Table 3 shows some examples of CTWs:

Table 3. Examples of CTWs

\begin{tabular}{||c|c|c|c|c||}
\hline CTW ID & ATW & Start & End & Task \\
\hline 1 & 1 & $1: 32: 54$ & $1: 33: 15$ & 1 \\
\hline 2 & 2 & $13: 36: 48$ & $13: 36: 59$ & 1 \\
\hline 3 & 3 & $3: 10: 36$ & $3: 10: 56$ & 2 \\
\hline 4 & 4 & $15: 12: 46$ & $15: 13: 43$ & 2 \\
\hline
\end{tabular}

In Table 3, the first row shows that this CTW (1:32:54-1:33:15) obscures the ATW 1 of task 1. Then the corresponding time of ATW 1 should be removed. After all the ATWs are pre-processed, the tasks can be calculated by an off-line algorithm. For the two kinds of satellites, they have the same off-line scheduling result. And the scheduling for traditional satellite is fixed, but the autonomous satellite can re-schedule the task sequence according to the changes of the cloud information. We change the start and end time of CTWs by 2-10 seconds to simulate the movement of clouds.

Five scenarios with two kinds of distribution modes are designed. As shown in Fig. 13(a), the targets are densely-distributed randomly in the area of China $\left(3^{\circ} \mathrm{N}-53^{\circ} \mathrm{N}, 73^{\circ} \mathrm{E}-133^{\circ} \mathrm{E}\right)$. And Fig. $13(\mathrm{~b})$ shows the distribution that targets are sparsely-distributed randomly worldwide. Table 4 listed the information of these five scenarios.

In Table 5, we use the reward rate to value the reliability of the system. It is clear that the reliability of the traditional satellite is much lower than that of the autonomous satellite. Although the traditional satellite has a high expected reward, the real reward is quite low because many pictures of the traditional satellite are obscured by clouds and the downloaded pictures are useless. By contrast, using the cloud detector, the autonomous satellite collects the realtime cloud information, re-schedules those targets that are obscured and downloads the cloud-free pictures. Therefore, the reliability of the autonomous satellite are much higher than the traditional nonautonomous satellite.

In order to show the effectiveness of the proposed distributed structure of autonomous satellite, we also compare the performance of this structure with the centralized structure of the satellite system. Compared with the centralized structure, this distributed structure has two advantages. The first one is the parallel computing of all the agents, making the online computing process fast. The other advantage is the higher 


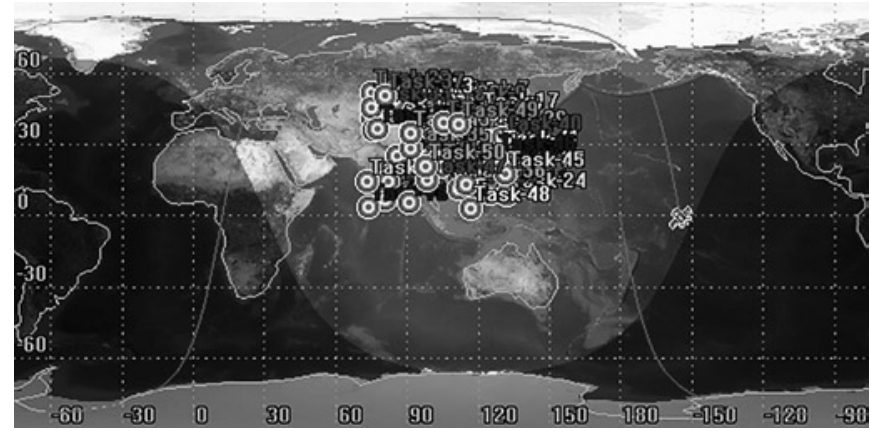

(a) Example of a densely-distributed scenario

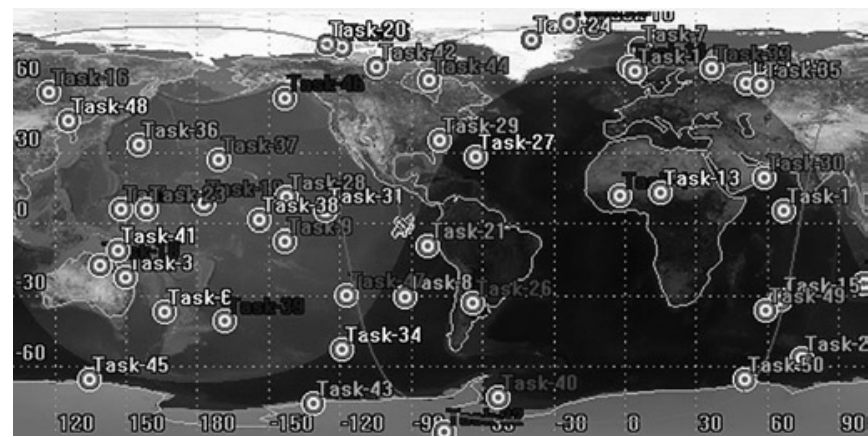

(b) Example of a sparsely-distributed scenario

Fig. 13. Diagram of two kinds of distribution modes

Table 4. Scenario list

\begin{tabular}{||c|c|c|c|c||}
\hline $\begin{array}{c}\text { Scenario } \\
\text { ID }\end{array}$ & $\begin{array}{c}\text { Number of } \\
\text { tasks }\end{array}$ & $\begin{array}{c}\text { Tasks with } \\
\text { ATWs }\end{array}$ & $\begin{array}{c}\text { Total prior- } \\
\text { ity }\end{array}$ & $\begin{array}{c}\text { Distribution } \\
\text { mode }\end{array}$ \\
\hline 1 & 40 & 38 & 243 & Dense \\
\hline 2 & 100 & 99 & 573 & Dense \\
\hline 3 & 100 & 99 & 487 & Sparse \\
\hline 4 & 150 & 149 & 863 & Sparse \\
\hline 5 & 200 & 200 & 1127 & Sparse \\
\hline
\end{tabular}

Table 5. Result list

\begin{tabular}{|c|c|c|c|c|c|}
\hline \multirow{2}{*}{$\begin{array}{c}\text { Scenario } \\
\text { ID }\end{array}$} & \multicolumn{3}{|c|}{ Traditional satellite } & \multicolumn{2}{c||}{ Autonomous satellite } \\
\cline { 2 - 6 } & $\begin{array}{c}\text { Expected } \\
\text { reward }\end{array}$ & Real reward & Reliability & Reward & Reliability \\
\hline 1 & 191.22 & 40.61 & $16.71 \%$ & 121.27 & $49.91 \%$ \\
\hline 2 & 386.11 & 241.40 & $42.13 \%$ & 357.74 & $62.43 \%$ \\
\hline 3 & 434.44 & 175.02 & $35.94 \%$ & 417.89 & $85.81 \%$ \\
\hline 4 & 755.95 & 306.90 & $35.56 \%$ & 715.68 & $82.93 \%$ \\
\hline 5 & 988.04 & 594.78 & $52.78 \%$ & 976.72 & $86.67 \%$ \\
\hline \hline
\end{tabular}

reliability. Because the agents are distributed on different processing units, the failure of one unit will not affect the others.

In this experiment, we simulate the circumstance of dynamic emergence of emergency tasks. There are two scenarios. In the first scenario, there are 200 tasks that are densely distributed in the task queue and the initial reliability is $70.54 \%$. In every five seconds, the system will add five tasks into the task queue. In the second scenario, there are 300 tasks that are sparsely distributed and the initial reliability is $100 \%$. In every five seconds, the system will add five tasks into the task queue. The results of the reliability change with the emergence of new tasks are reported respectively in Fig. 14(a) and (b). As is shown, the distributed structure has a higher reliability for the online computing of new emergency tasks. With the emergence of

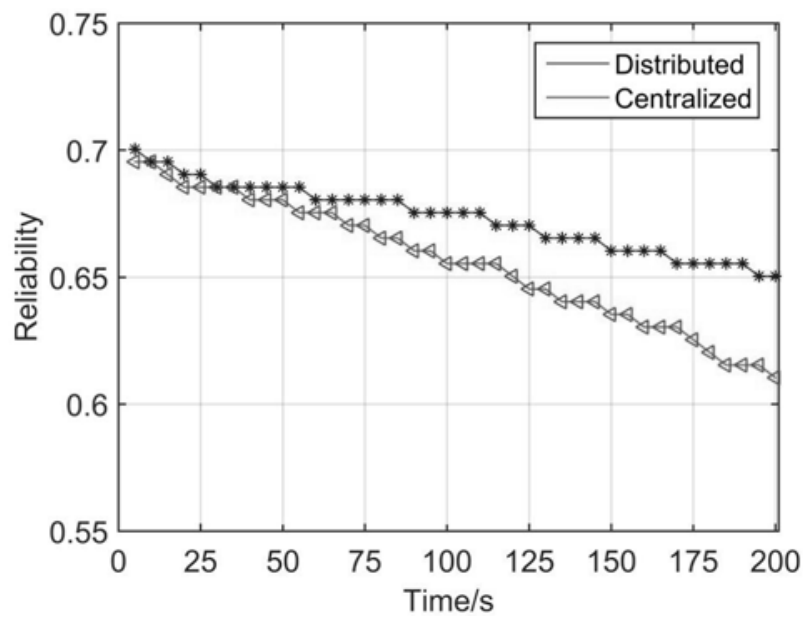

(a) Scenario 1

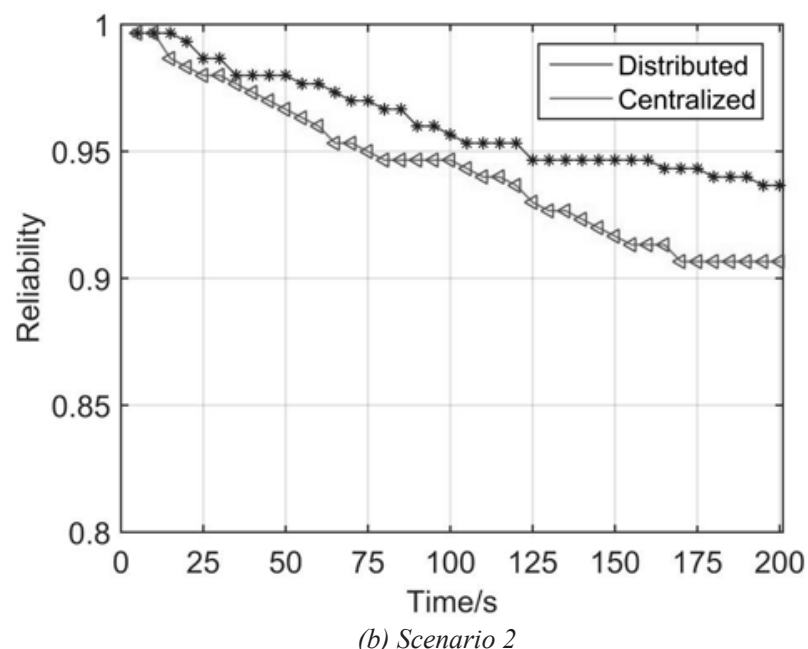

Fig. 14. The reliability change when adding new tasks to the system.

new tasks, the reliability of the centralized structure declines much faster than that of the distributed structure due to the lack of parallel computing.

In Table 6, we analyze the reliability change when different agents fail for both the distributed structure and the centralized structure. In this experiment, we design a scenario with 40 densely distributed tasks and five emergency tasks. The emergency tasks are not visible for the ground station and should be found by the satellite itself. And using this scenario, we test the reliability of the system when each of the agents fails. The result is reported in Fig. 15.

Fig. 15 The reliability of the system when each agent fails

From Fig. 15, we can see that for the centralized structure, if one of the agents fails or the blackboard fails, the satellite will become a non-autonomous satellite and the system reliability will be seriously affected. By contrast, for the proposed distributed structure, if one of the agents fails, the reliability is affected little. If the pre-processing agent and the sensing agent fail, the satellite cannot find new emergency tasks. If the plan-scheduling agent fails, the satellite cannot perform an online re-planning process so the reliability will be affected more. Due to the restricted space environment, the satellite can hardly be maintained and repaired after it is launched into space. Therefore, for the important processing unit, like the planning and scheduling agent in this paper, some redundancy can be used. The significance of other software and hardware units can also be calcu- 
Table 6. The reliability analysis when different agents fail

\begin{tabular}{|c|c|c|}
\hline Agent type & Distributed structure & Centralized structure \\
\hline Pre-processing & $\begin{array}{l}\text { The online calculation of VTWs fails. But for the tasks generated on the ground, } \\
\text { the calculation can be done on the ground. This reliability is not affected. }\end{array}$ & \multirow{6}{*}{$\begin{array}{l}\text { All the agents are in tegrated on the one } \\
\text { processing unit. If this unit fails, the whole } \\
\text { system cannot work like an autonomous } \\
\text { satellite. The satellite becomes a non-auton- } \\
\text { omous satellite. }\end{array}$} \\
\hline Plan-scheduling & $\begin{array}{c}\text { The online planning and scheduling ability fails. The satellite can still find new } \\
\text { tasks, report and observe targets according to ground orders. The reliability is } \\
\text { much higher than a non-autonomous satellite. }\end{array}$ & \\
\hline Belief & $\begin{array}{l}\text { This failure will cause a wrong estimation of satellite resource such as the bat- } \\
\text { tery volume, making some of scheduled tasks fail. The reliability will be affected } \\
\text { a little. }\end{array}$ & \\
\hline Data processing & $\begin{array}{l}\text { Because parts of failed tasks cannot be found and deleted, some memory capacity } \\
\text { will be wasted. The planning and scheduling are not affected. }\end{array}$ & \\
\hline Sensing & $\begin{array}{l}\text { The satellite cannot find new tasks by itself, but the current reliability is not af- } \\
\text { fected. }\end{array}$ & \\
\hline User interface & The system's reliability is not affected. & \\
\hline Blackboard & - & $\begin{array}{l}\text { The whole system cannot work anymore. } \\
\text { The satellite becomes a non-autonomous } \\
\text { satellite. }\end{array}$ \\
\hline
\end{tabular}

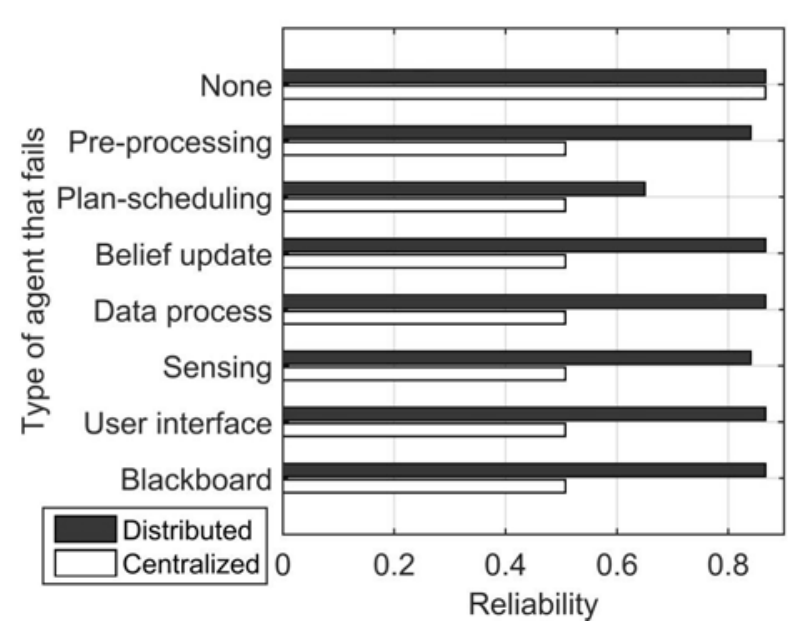

Fig. 15. The reliability of the system when each agent fails

lated and ranked, in order to introduce redundancy for the important ones to improve the reliability of the whole satellite system [11].

In above, the proposed online scheduling algorithm and the distributed multi-agent blackboard structure are efficient and effective for the autonomous satellite.

\section{Conclusions}

With the wide application of satellite technology, the traditional satellite controlling mode becomes unable to meet requirements of new complex tasks. In order to solve the problems of rapid response to emergencies, the environment uncertainties and the satellite faults, the new-generation autonomous satellite has become the focus of the satellite development.
In this paper, an autonomous multi-sensor satellite system based on the distributed multi-agent blackboard model is designed. Seven agents with different functions are designed. The agents interact with each other through the blackboard. The blackboard stores the satellite status information, task queue and action sequence, which are regarded as the belief set, desire set and intention set respectively. An adaptive rule-based heuristic scheduling algorithm is used to schedule the tasks. Four different operators are designed. And a fast forward search planning algorithm based on STRIPS is designed. The prototype system is realized by Jade 4.0. Four kinds of events are designed to verify the system's autonomy. The simulation experiments verify that the system can deal with the four kinds of events without human intervention, which greatly improves the performance and reliability of the satellite. The performance of the proposed algorithms and the distributed multi-agent blackboard structure is proved.

This work proves the effectiveness of using multi-agent technology to build the autonomous satellite system and contributes the distributed multi-agent blackboard model, which shows a high reliability and performance for those dynamic, uncertain and complex tasks. This structure also has high reconfigurability and extendibility. The blackboard model structure can be used to establish the future autonomous satellite system structure. The next focus of this research is to build a multi-satellite system using multi-agent technology to deal with concurrent processing and cooperative behaviors of the satellite constellation.

\section{Acknowledgement}

This paper is supported by National Natural Science Foundation of China (Grant No. 71501180 and 71501179) and the Foundation for the Author of National Excellent Doctoral Dissertation of China (Grant No. 201492). Thanks are due to the referees for their valuable comments.

\section{References}

1. Armstrong M. Joint reliability importance of elements. IEEE Transactions on Reliability 1995; 44(3): 408-412, https://doi. org/10.1109/24.406574.

2. Birnbaum Z. On the importance of different components in a multicomponent system. In P. Krishnaiah (Ed.), Multivariate Analysus-II. New York: Academic Press 1969.

3. Borgonovo E, Apostolakis G. A new importance measure for risk-informed decision making. Reliability Engineering and System Safety 2001; 72: 193-212, https://doi.org/10.1016/S0951-8320(00)00108-3. 
4. Caskurlu B, Mkrtchyan V, Perekh O, Subramani K. On Pratial Vertex Cover and Budgeted Maximum Coverage Problems in Bipartite Graphs. Theoretical Computer Science: 8th IFIP TC 1/WG 2.2 International Conference, TCS 2014, Rome, Italy: Springer 2014; $13-25$.

5. Curtis D E, Pemmaraju S V, Polgreen P. Budgeted Maximum Coverage with Overlapping Costs: Monitoring the Emerging Infections Network. 2010 Proceedings of the Twelfth Workshop on Algorithm Engineering and Experiments (ALENEX). Society for Industrial and Applied Mathematics 2010.

6. Du D, Ko K, Hu X. Design and analysis of appromaxition algorithms. Springer Optimization and Its Applications 2012, https://doi. org/10.1007/978-1-4614-1701-9.

7. Ericson II C A. Hazard Analysis technique for System Safety. New Jersey: John Wiley \& Sons 2015

8. Espitrity J, Coit D, Prakash U. Component criticalty importance measures for the power industry. Electric Power Systems Research 2007; 407-420, https://doi.org/10.1016/j.epsr.2006.04.003.

9. GLPK (GNU Linear Programming Kit) From: www.gnu.org/software/glpk

10. Gupta S, Bachttacharya J, Barabady J, Kumar U. Cost-effective importance measure: A new approach for resource prioritization in a production plant. International Journal of Quality \& Realibility Management 2013; 30 (4): 379-386, https://doi.org/10.1108/02656711311308376.

11. Khuller S, Moss A, Naor J. The budgeted maximum coverage problem. Information Processing Letters 1999; 70 (1): 39-45, https://doi. org/10.1016/S0020-0190(99)00031-9.

12. Kuo W, Zhu X. Importance measures in reliability, risk and optimization. Chichester: John Whiley \& Sons 2012, https://doi. org/10.1002/9781118314593.

14. Rauzy A. A Benchmark of Boolean Formulae. From http://iml.univmrs.fr/ arauzy/aralia/ benchmark.htm

15. Revelle C S. A bibliography for some fundamental problem categories in discrete location science. European Journal of Operational Research, 2008; 184 (3): 817-848, https://doi.org/10.1016/j.ejor.2006.12.044.

16. Van der Borst M, Schoonakker H. An overview of PSA importance measures. Reliability Engineering and System Safety, 200172 (3): 241 245, https://doi.org/10.1016/S0951-8320(01)00007-2.

17. van Heuven van Staereling I, de Keijzer B, Schafer G. The Ground-Set-Cost Budgeted Maximum Coverage Problem. 41st International Symposium on Mathematical Foundations of Computer Science (MFCS 2016). Dagstuhl Research Online Publication Server, 2016

18. Vaurio J. Ideas and developments in importance measures and fault-tree techiques for reliability and risk analysis. Reliability Engineering and System Safety, 2010; 95: 99-107, https://doi.org/10.1016/j.ress.2009.08.006.

19. Vesely W, Davis T, Denning R, Saltos N. Measures of risk importance and their applications. Columbus: Battelle Columbus Labs, OH (USA), 1983, https://doi.org/10.2172/5786790.

20. $\mathrm{Wu} \mathrm{S.} \mathrm{Joint} \mathrm{importance} \mathrm{of} \mathrm{multistate} \mathrm{system.} \mathrm{Computers} \mathrm{\&} \mathrm{Industrial} \mathrm{Engineering,} \mathrm{2005;} \mathrm{49:} \mathrm{63-67,} \mathrm{https://doi.org/10.1016/j.}$ cie.2005.02.001.

21. Wu S, Coolen F. A cost-based importance measure for system components: An extension of the Birnbaum importance. European Journal of Operational Research, 2013; 189-195, https://doi.org/10.1016/j.ejor.2012.09.034.

22. Zafiropoulos E P, Dialynas N E. Methodology for the optimal component selection of electronic devices under reliability and cost constraints. Quality and Reliability Engineering International, 2007; 23 (8): 885-897, https://doi.org/10.1002/qre.850.

23. Zaitseva E, Levashenko V, Kostolny J. Application of logical differential calculus and binary decision diagram in importance analysis. Eksploatacja i Niezawodnosc - Maintenance and Reliability 2015; 17 (3): 379-388, https://doi.org/10.17531/ein.2015.3.8.

24. Zio E. Risk importance measures. In H. Pham (Ed.), Safety importance measures and its applications. London: Springer, 2011; 151-196, https://doi.org/10.1007/978-0-85729-470-8_6.

25. Zio E, Podofilini L. Accouniting for components interactions in the differential importance measure. Reliability Engineering and System Safety, 2006; 91: 1163-1174, https://doi.org/10.1016/j.ress.2005.11.044.

26. Zio E, Podofilini L. The use of importance measures for the optimization of multi-state systems. Eksploatacja i Niezawodnosc - Maintenance and Reliability 2006; 2: 33-36.

\section{Lei HE \\ Guoliang LI \\ Lining XING \\ Yingwu CHEN}

College of Information System and Management

National University of Defense Technology

No.47 Yanwachi Street, Changsha, China, 410073

E-mails: helei@nudt.edu.cn, worldchinali@126.com, xing2999@qq.com, ywchen@nudt.edu.cn 